\title{
Greenhouse gas emissions from conventional and organic cropping systems in Spain. II. Fruit tree orchards
}

\author{
Eduardo Aguilera • Gloria Guzmán • Antonio Alonso
}

Accepted: 17 October 2014 / Published online: 28 November 2014

(C) INRA and Springer-Verlag France 2014 carbon accumulation when fruit tree orchards substitute herbaceous crops (IPCC 2006). This biomass can be harvested when plantations are renewed and then burned in substitution of fossil fuels or temporally sequestered as wood products. Fruit tree orchards also produce large amounts of residual biomass in the form pruning residues, which can be used for soil conditioning, animal feeding, or for energetic purposes (e.g., Infante-Amate and González de Molina 2013; Kroodsma and Field 2006). Fruit tree orchards were estimated to supply ca. $80 \%$ of total fuelwood consumed in Spain in the year 2000 (Infante-Amate et al. 2014). In addition, cover crops can be established below the trees protecting the soil from erosion, contributing to soil carbon sequestration (GonzálezSánchez et al. 2012; Aguilera et al. 2013a) and potentially serving as animal feed (Ramos et al. 2011). In spite of these promising features, there is some concern about the temporal limitation of soil carbon sequestration, which would only occur until a new equilibrium is reached. For example, González-Sánchez et al. (2012) observed that C sequestration rate under cover crops in Spanish fruit tree orchards was $1.59 \mathrm{Mg} \mathrm{C} / \mathrm{ha}$ in short-term ( $<10$ years) experiments and $0.35 \mathrm{Mg} \mathrm{C} / \mathrm{ha}$ in long-term ( $>10$ years) experiments. On the other hand, tree cropping systems following forest may induce a decrease in soil organic carbon, at least during the establishment period (Noponen et al. 2013), all of which suggests that there is a need to optimize the management in order to maximize soil quality and carbon content in orchards.

Woody perennial crops usually dominate the landscape and the rural economy in producing areas of the Mediterranean region. They include many species originally domesticated in this climatic area and, sometimes, biophysically limited to it. The specialization of olive, grape, and citrus production was largely responsible for the agricultural modernization in the Mediterranean, driven by the growing demand from an expanding world market of these commodities, but they were made possible by the multifunctional character of
E. Aguilera $(\bowtie) \cdot$ G. Guzmán · A. Alonso

Agro-ecosystems History Laboratory, Universidad Pablo de Olavide, Carretera de Utrera, km. 1, 41013 Seville, Spain

e-mail: emagufer@upo.es

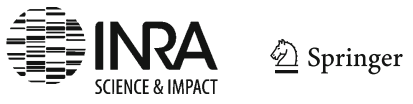


Mediterranean woody systems (Infante-Amate and González de Molina 2013). The relevance of fruit tree orchards has grown further in the last decades with the expansion of new commercial crops such as pip and stone fruits, subtropical fruits, and some treenuts. The expansion of perennial woody systems such as vineyards and orchards in California has been associated to the accumulation of significant amounts of carbon in their living biomass (Kroodsma and Field 2006). Also in Andalucía, in South Spain, an increase in vegetation carbon stocks between 1956 and 2007 was partially associated to the expansion of permanent crops (Muñoz-Rojas et al. 2011).

Fruit tree orchards also supply a relevant fraction of the Spanish diet, representing nearly $20 \%$ of dietary energy intake according to FAOSTAT (FAO 2014), mainly in the form of olive oil. Nowadays, almost one third of the total cropland and about one half of organic cropland in Spain are cropped to fruit tree orchards (MAGRAMA 2011). The high relative importance of woody systems under organic farming is probably influenced by the availability of self-produced organic matter sources allowing to better close nutrient cycles. Specific features of organic farming could further improve the contribution of fruit tree orchards to climate change mitigation. Reduced fossil energy consumption in organic orchards (Guzmán and Alonso 2008; Alonso and Guzmán 2010) suggests that there may also exist greenhouse gas emissions savings in these systems, taking into account the high importance of energy-related emissions in the carbon footprint of herbaceous Spanish cropping systems (Aguilera et al. 2014). At the soil level, evidence suggests low $\mathrm{N}_{2} \mathrm{O}$ emissions associated to organic fertilizers (Aguilera et al. 2013b) and higher soil organic carbon (SOC) stocks in organically managed soils under Mediterranean climate (Aguilera et al. 2013a). All these features point to a large mitigation potential of Mediterranean fruit tree orchards and particularly of organic agro-ecosystems, but comprehensive assessments of their global warming potential are very scarce.

In the present work, we applied life-cycle assessment (LCA) methodology to analyze the full greenhouse gas emission balance of the most relevant perennial cropping systems in Spain and compare the performance of organic and conventional management. The analysis included all emissions involved at the production step, incorporating specific $\mathrm{N}_{2} \mathrm{O}$ emission factors and estimations of carbon sequestration and fuel wood coproduction. We calculated the balances following LCA procedures, with the following objectives:

1. Determine the influence of organic management on areabased and product-based greenhouse gas emissions in a range of fruit tree orchards representing organic production in Spain

2. Identify critical processes implied in the global warming potential of organic and conventional Mediterranean fruit tree orchard products.
3. Analyze the effect of carbon sequestration rate calculation and coproduct consideration on the total global warming potential.

4. Identify critical options for improving the carbon footprint of organic and conventional Mediterranean fruit tree orchard products.

\section{Methods}

\subsection{Data collection}

Information on management and production features was obtained from personal interviews to a representative sample composed of 42 pairs of organic and conventional farmers in Spain, as described in Alonso and Guzmán (2010). Two cases were added to this set of interviews, one for vineyards and one for carob tree. In addition, to account for the large change occurred in olive organic management in the last 5 years, four olive cases $(4,5,6,7)$ were substituted for more recent interviews, performed in 2012. The complete database comprised 16 crop species, grouped by 6 crop types: citrus, including mandarins (2 pairs of interviews) and oranges (3); fruits, including apples (4), pears (2), plumb (1), table grapes (1), peach (1), apricot (1), and figs (2); subtropical fruits, including avocado (2), mango (1), and bananas (2); treenuts, including almonds (3), hazelnuts (2), and carob tree (1); vineyards, including grapes for wine (7); and olives (7 pairs). Banana was included in the subtropical fruit category despite being a herbaceous crop because of its similarities with tree orchard cropping systems.

\subsection{LCA scope}

An attributional LCA was performed based on the "cradle to farm-gate" perspective, which considers all inputs and processes for the plant production as well as all the necessary upstream processes (see details in Aguilera et al. Submitted to this issue). The temporal boundaries were adjusted to 100 years as recommended by IPCC (2006). This extends the study to the full life cycles of the studied crops, including the unproductive years of perennial cropping systems and long-term soil carbon dynamics. Unproductive period of perennial cropping systems was estimated according to cropping cycle data from Fernández-Escobar (1988). Tree crop plantation cycles were divided into three periods: (i) implantation period, with no yield and $50 \%$ fertilizer rate; (ii) growing period, with $50 \%$ yield and $50 \%$ fertilizer rate; and (iii) fullproduction period, with $100 \%$ yield and $100 \%$ fertilizer rate. Net emissions in the implantation and growing periods were computed as "unproductive stages" in the impact assessment. 
Carbon accumulation in the living biomass was not considered a carbon sink, as plantation surfaces were assumed to be stable in time. However, this biomass is commonly used as fuelwood after plantation removal, so its annual accumulation was quantified. In the same way, pruning residues are usually burned in the field or more recently incorporated to the soil, but a non-negligible share (the thick branches) is commonly used as fuelwood (Infante-Amate and González de Molina 2013). Economic allocation was applied to total fuelwood coproduction (removals and prunings) in the main analysis. Economic value of the crop products and the fuelwood was obtained mainly from CAPMA (2013) and MAGRAMA (2009).

\subsection{Carbon footprint method}

\subsubsection{Emissions from the production of inputs}

Data on material and energy consumption associated to the agricultural operations were estimated according to Alonso and Guzmán (2010) with modifications described in Aguilera et al. (Submitted to this issue). Emission factors for the production of inputs from the technosphere were mainly obtained from databases in SimaPro 7.2 software (PRè Consultants 2010), as described in Aguilera et al. (Submitted to this issue). In the case of seeded cover crops, emission values for the production of legume and cereal seeds were taken from Aguilera et al. (op. cit.).

\subsubsection{Production and destinies of crop residues}

Pruning residue dry matter production was calculated using residue indexes from Guzmán et al. (2014). The only information on residue management available in the interviews referred to the cases in which it was mulched and incorporated to the soil. In the remaining cases, we assumed that $78 \%$ of the prunings were burned (MARM 2008), and $22 \%$ represented a coproduct. The same fraction was assumed to be a coproduct in the cases in which the residue was mulched. Living biomass accumulation in fruit tree orchards was estimated from pruning values using a relationship of $0.68 \mathrm{~kg}$ accumulated dry matter per kilogram of pruned dry matter (Roccuzzo et al. 2012). This value was roughly validated through interviews to companies in the sector.

\subsubsection{Direct field emissions}

$\mathrm{N}_{2} \mathrm{O}$ emissions were estimated from $\mathrm{N}$ inputs using specific Mediterranean data for direct emissions and IPCC (2006) default procedures for indirect emissions, as described in Aguilera et al. (Submitted). Specific Mediterranean $\mathrm{N}_{2} \mathrm{O}$ emission factors are $0.08,0.66$, and $1.01 \%$ of applied $\mathrm{N}$ emitted as $\mathrm{N}_{2} \mathrm{O}-\mathrm{N}$ for rainfed, drip irrigation, and high-water irrigation systems, respectively. $\mathrm{N}$ content in residues was taken from Bilandzija et al. (2012) and Roccuzzo et al. (2012). The $\mathrm{N}$ fixed by legumes in cover crops was included as an input using own data estimated in field (unpublished). No $\mathrm{N}$ fixation was assumed for soils without cover crops, whereas in extensive systems (vineyards, olives, and treenuts), $20 \mathrm{~kg} \mathrm{~N} / \mathrm{ha}$ was fixed by spontaneous cover crops and $45 \mathrm{~kg}$ by legume-seeded cover crops. In intensive systems (citrus, fruits, and subtropical fruits), 35 and $75 \mathrm{~kg} \mathrm{~N}$ were fixed in spontaneous and legume-seeded cover crops, respectively. Emissions of $\mathrm{N}_{2} \mathrm{O}$ and $\mathrm{CH}_{4}$ from biomass burning were calculated using IPCC (2006) factors of $0.07 \mathrm{~g} \mathrm{~N}_{2} \mathrm{O}$ and $2.7 \mathrm{~g} \mathrm{CH}_{4}$ emitted per kilogram of dry matter burnt.

\subsubsection{Carbon sequestration}

Soil carbon sequestration is the result of a balance between carbon inputs and outputs, dependent on management practices and agro-climatic conditions, and limited in time until a new equilibrium is reached. Soil carbon balance was modeled based on the results of the meta-analysis on carbon sequestration under Mediterranean conditions by Aguilera et al. (2013a), including some unpublished data from the same study and some data from other references. Soil carbon was assumed to be in equilibrium under conventional tillage with no organic inputs. The management of tillage and organic inputs determined soil $\mathrm{C}$ sequestration rate in the remaining cases during the initial simulation period ( $0-20$ years), according to the average experimental values analyzed. No tillage without cover crops was associated to a net emission of $0.13 \mathrm{Mg} \mathrm{C} / \mathrm{ha}$. Cover crops in woody cropping systems induced a net carbon sequestration rate of $-0.27 \mathrm{Mg} \mathrm{C} / \mathrm{ha}$. This value can be considered conservative, for example, when compared with the mean values for Spanish cover crops reported by González-Sánchez et al. (2012). It was assumed that $30.5 \%$ of the $C$ contained in external organic inputs such as manures, composts, and manufactured organic fertilizers was incorporated to the soil and thus contributed to net $\mathrm{C}$ accumulation. This number is the median value $(N=25)$ of the percentage of $\mathrm{C}$ input contributing to net $\mathrm{C}$ sequestration in "organic amendments," "recommended management practices," and "slurry" categories in Aguilera et al. (2013a). We found no specific data for pruning residues, so we used the same coefficient as for the other inputs. Carbon content of residues and organic amendments was taken from Bilandzija et al. (2012). The resulting net soil carbon exchange is shown in Table 1. In the impact assessment, the model was adjusted to 100 years by considering that average $\mathrm{C}$ sequestration rate in the $0-100$-year period was $50 \%$ of that in the initial $0-20$ year period, based on the average change in published longterm modeling studies (Hansen et al. 2006; Powlson et al. 2008; Alvaro-Fuentes and Paustian 2011). 


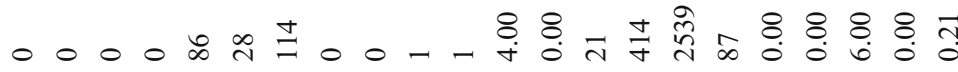

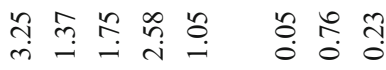

○ 0 0 ㅅ

○ 0 ○

○ ○ ○

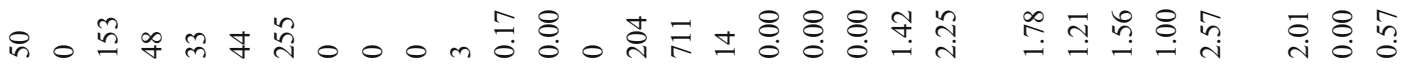

饥

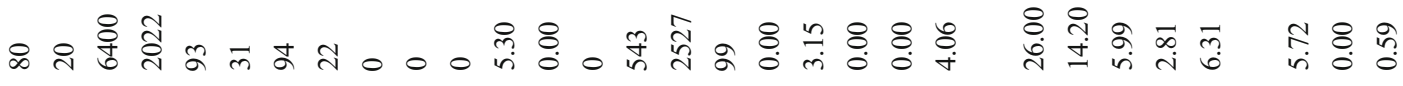

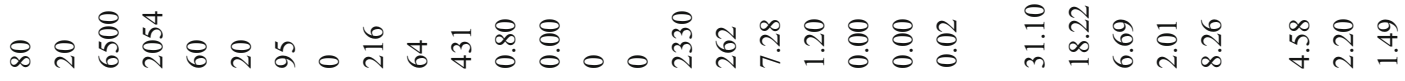

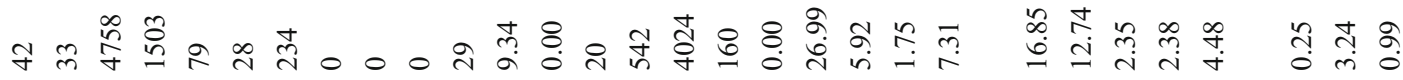

f

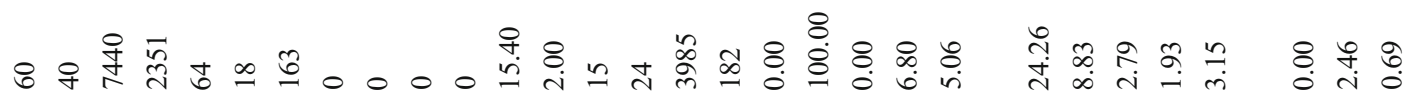

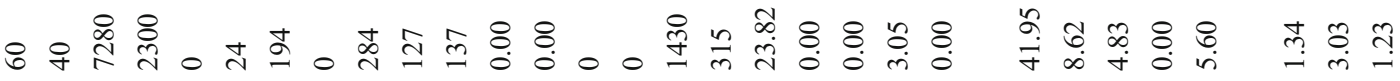

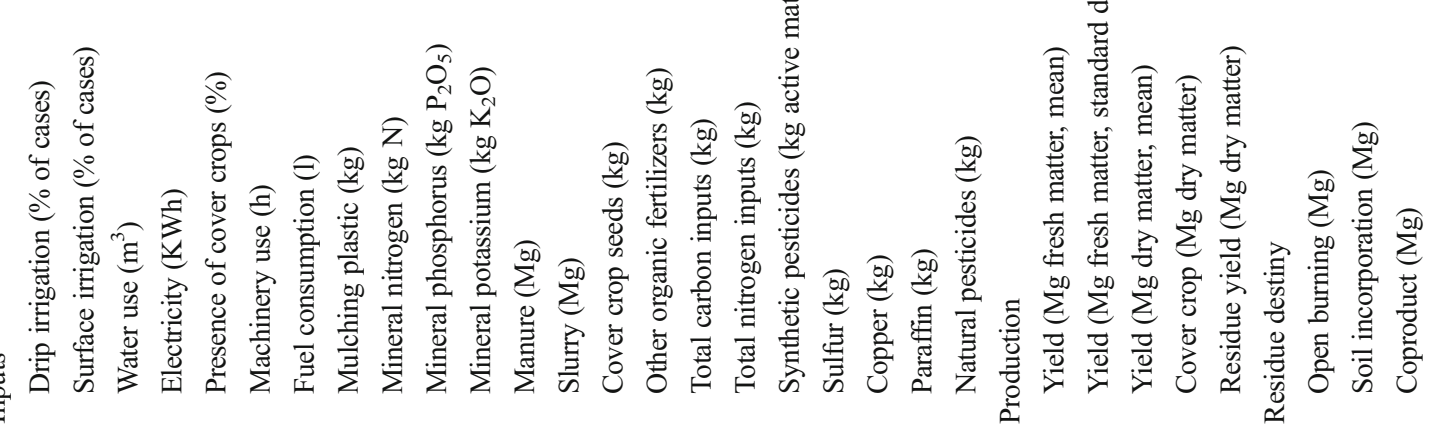


2.4 Sensitivity analysis

The effect of applying different methods for the estimation of $\mathrm{C}$ sequestration was examined in olives. The baseline scenario (Base 100-y) was compared with the reduction of the study time frame to 20 years (Base 20-y). The results were also compared with IPCC (2006) approach for 20 and 100 years time horizons (respectively, IPCC 100-y and IPCC 20-y). In IPCC methodology, C stocks are calculated for each cropping system before and after management changes on the basis of soil, climate, soil management, and qualitative information on carbon input. The olive farms studied were assumed to have high-activity clay soils and warm temperate dry climate.

In many occasions wood coproducts do not have a direct economic value for the farmers, as removals are usually done by companies which are paid in wood, and tree prunings are usually consumed domestically. In order to account for this uncertainty, and to understand the physical role of fuelwood coproduction in woody systems, we quantified the effect of other allocation methods and system expansion in a sensitivity analysis of treenut systems. These methods have different meaningfulness depending on the research question, as the functions performed by nuts and wood are of a very different nature. Treenut coproduct scenarios include product allocation (Product), in which all emissions are allocated to the main product; economic allocation (Economic); mass allocation (Mass); and system expansion (Expansion), in which wood coproducts are assumed to substitute natural gas for domestic heating purposes. The substitution of natural gas by wood was based on their calorific value. The effect of this substitution was calculated taking into account emissions during the combustion process of each type of fuel, as modeled in ecoinvent (ecoinvent Centre 2007).

\section{Results and discussion}

\subsection{The greenhouse gas profiles of the studied systems}

High variability within the studied categories, which include different study sites and management characteristics, and sometimes different crop species, leads to a high variability of yields and carbon footprints (Tables 1 and 2). Organic and conventional study cases were pair-wise selected to improve comparability, but this variability indicates that the mean values presented here should be taken with care (Fig. 1). On the other hand, some of the sources of variation regarding the actual application of management practices and the methodological assumptions will be discussed in this section and in Sections 3.2 and 3.3. 


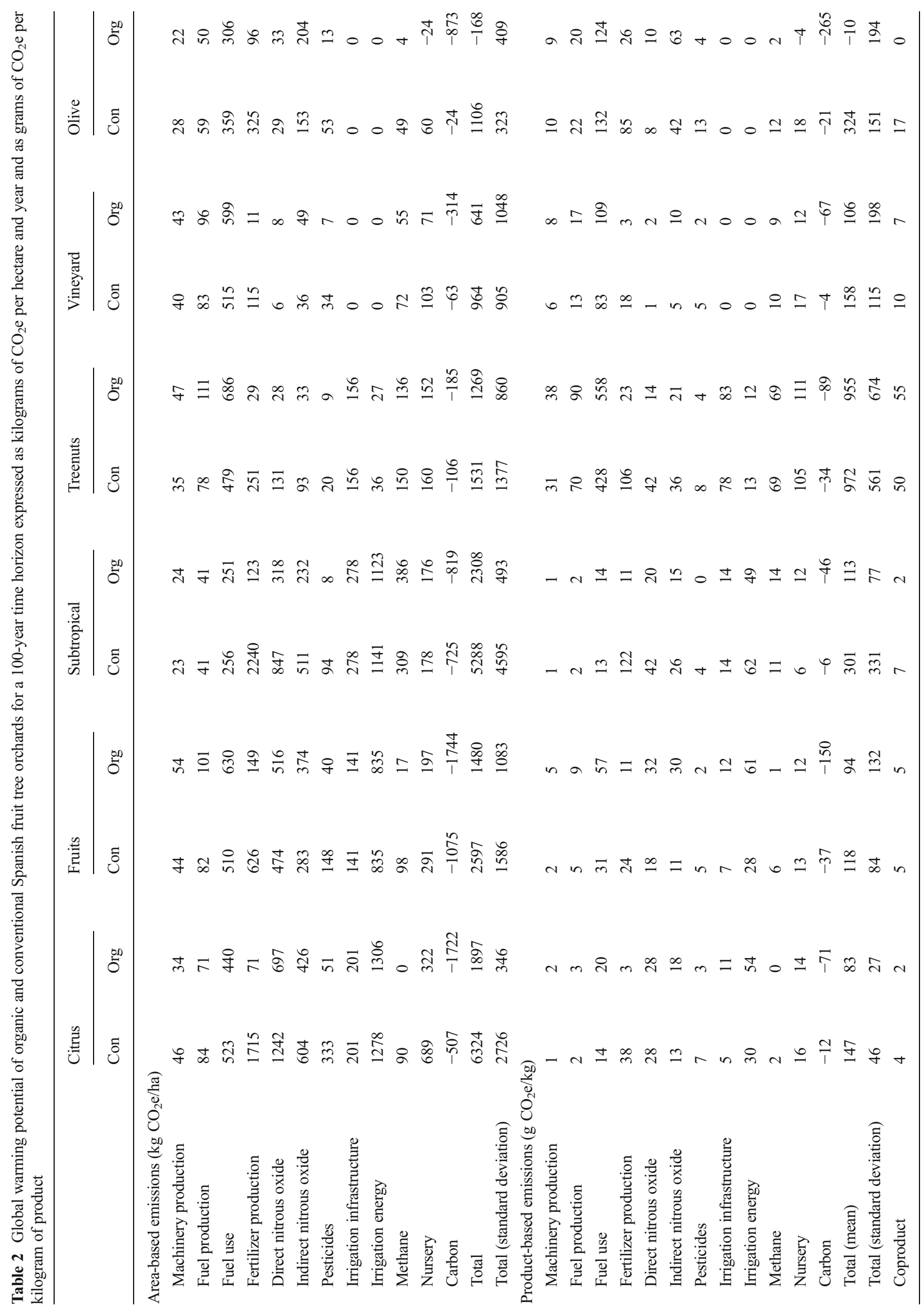


Fig. 1 Conventional (left) and organic (right) olive orchards in South Spain

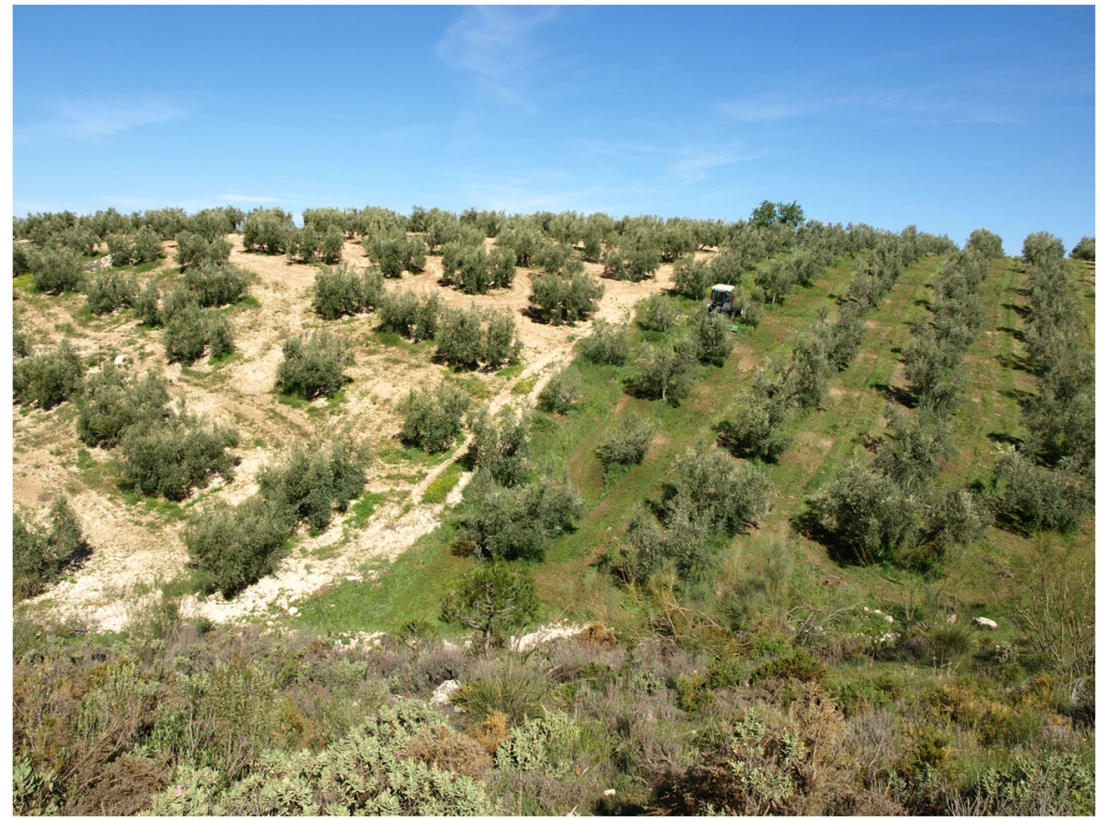

\subsubsection{Irrigated fruits}

Citrus orchards are very intensive systems with high inputs of irrigation water, fertilizers, and pesticides (Table 1). They reach the highest irrigation rates and also the highest $\mathrm{N}$ application rates of the studied systems, with 301 and $184 \mathrm{~kg} \mathrm{~N} / \mathrm{ha}$ under conventional and organic management, respectively. Consequently, they also show the highest greenhouse gas emission rates per hectare, with 6.8 and $3.5 \mathrm{Mg} \mathrm{CO}_{2} \mathrm{e}$ excluding carbon sequestration. The major decrease in organic systems occurs in fertilizer production and $\mathrm{N}_{2} \mathrm{O}$ emissions (Table 2). When including carbon sequestration, emissions are greatly reduced in organic farms, down to $1.9 \mathrm{Mg} \mathrm{CO}_{2} \mathrm{e}$ / ha, as compared to $6.3 \mathrm{Mg} \mathrm{CO}_{2} \mathrm{e}$ in conventional ones, which was mainly due to high carbon inputs in the form of pruning residues and manures. Although cover crops were adopted in only $64 \%$ of the cases, internal carbon inputs represented more than half of total carbon inputs in organic citrus systems. Emissions per kilogram of product were relatively low in citrus fruits due to high yields, and average conventional crop emissions of $147 \mathrm{~g} \mathrm{CO}_{2} \mathrm{e} / \mathrm{kg}$ were comparable with the global estimation by Nemecek et al. (2012), while emissions of organic citrus products averaged $83 \mathrm{~g} \mathrm{CO}_{2} \mathrm{e} / \mathrm{kg}$. Both values are very similar to those obtained by Pergola et al. (2013) in Sicily, despite these authors did not consider carbon sequestration. In our case, the differences with conventional management in the product-based global warming potential were only due to carbon sequestration, as the other reductions were offset by lower yields.

The analyzed "Fruit" group represents a broad range of tree species and management intensities, from heavily irrigated and fertilized cases, such as some apples and pear orchards, to rainfed fig tree orchards with almost no $\mathrm{N}$ input even under conventional management. This results in a great variability of greenhouse gas emission profiles, although the general composition was similar to that of citrus production, with a relative increase in the contribution of machinery (Fig. 2a). On average, emissions per kilogram of product were lower under organic management, but as observed in citrus products, this only occurred when carbon sequestration was considered (Table 2).

Subtropical fruits repeat the same emission pattern of citrus and fruits, with a global warming potential more or less evenly distributed between fertilizer production, irrigation, and nitrous oxide as the major contributors under conventional management, while irrigation, nitrous oxide, and soil carbon (negative) were the most important under organic management. Yield differences between organic and conventional were not very large in subtropical fruits (Table 1), resulting in a very good performance of organic products (Fig. 2b), despite carbon sequestration did not contribute as much to the carbon footprint (Fig. 2a). It is worth noting the great variability between cases, and especially the high carbon footprint of conventional banana production, of $641 \mathrm{~g} \mathrm{CO}_{2} \mathrm{e} / \mathrm{kg}$, which was associated to a high consumption of fertilizers, and can be compared with $49 \mathrm{~g} / \mathrm{kg}$ of organic bananas (data not shown) and with a global estimation of $250 \mathrm{~g} \mathrm{CO}_{2} \mathrm{e} / \mathrm{kg}$ (Nemecek et al. 2012).

\subsubsection{Treenuts}

Treenut emissions are dominated by machinery use (Fig. 2a), as was also observed in Spanish herbaceous rainfed systems (Aguilera et al. Submitted). In fact, although our treenut sample includes two pairs of irrigated systems and three pairs 


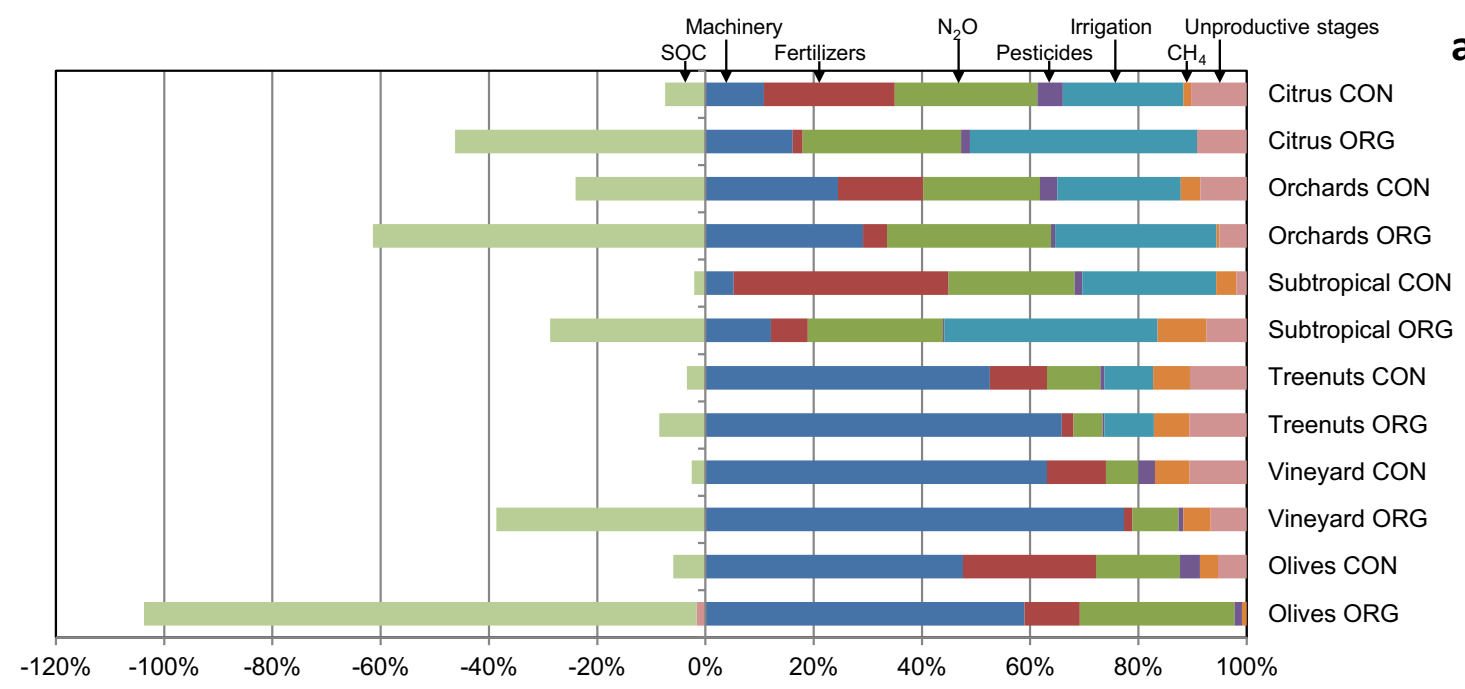

$\mathrm{g} \mathrm{CO}_{2}$-eq kg-1

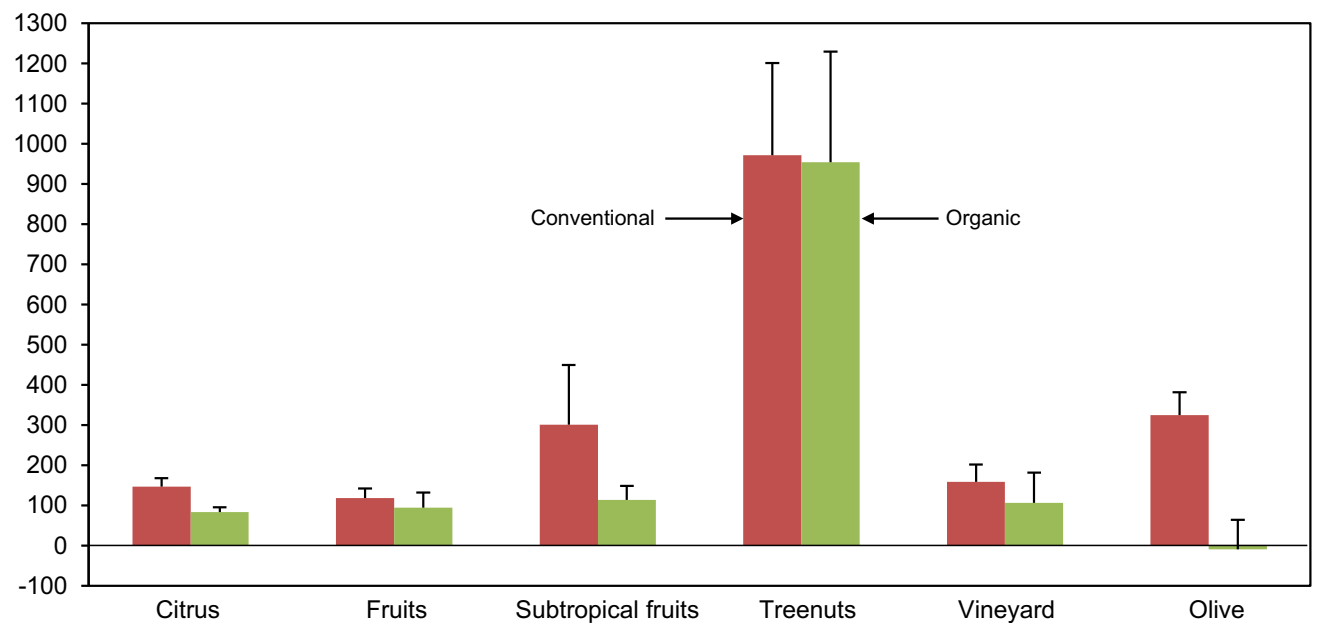

Fig. 2 Global warming potential $\left(\mathrm{g} \mathrm{CO}_{2}\right.$-eq $/ \mathrm{kg}$ ) of the six types of crop products and the two types of management (Conventional, Con; Organic, Org) studied, expressed as the breakdown of the main processes implicated and as the net balance resulting from subtracting carbon sequestration to total emissions (means with standard errors). The components of the emission balance comprise Unproductive stages, which include the impact of the inputs used in the initial and final periods of the plantation;

$\mathrm{CH}_{4}$ from biomass burning; Pesticide production; $\mathrm{N}_{2} \mathrm{O}$, including soil emissions, indirect emissions, and biomass burning emissions; Fertilizer production, including fertilizer production and transport; Machinery production and use, including fuel production and use; and $S O C$, which accounts for the changes in soil organic carbon resulting from management practices

of rainfed ones, the use of water and fertilizers is very low in all cases. Productivity is also low in terms of fresh matter, but similar to other rainfed crops such as olives and vineyards in terms of dry matter (Table 1). Product-based emissions of treenuts had averages of 972 and $955 \mathrm{~g} \mathrm{CO}_{2} \mathrm{e} / \mathrm{kg}$ under conventional and organic management. The calculated values agree with world average emissions for almonds and hazelnuts estimated by Nemecek et al. (2012) and were lower than those associated to almond production in California reported by Venkat (2012). Higher emissions in California can be explained by a heavier use of water and pesticides and a lower productivity. In our sample, treenuts were the crop type with the worst relative performance of organic management. On average, no differences with their conventional counterparts could be observed. When compared with the other types of cropping systems, the reason seems to be a very low carbon sequestration rate in organic systems due to the low rate of adoption of soil-protecting practices such as cover cropping (33\%) and pruning mulching $(0 \%)$. These techniques are only gradually being introduced in tree crop cultivation in Spain, as the unfavorable policy framework was preventing their expansion.

\subsubsection{Vineyards}

Machinery use accounted for more than $60 \%$ of the total global warming potential of vineyards (Fig. 2). The contribution of methane from open biomass burning was also 
important, as a result of the high amount of pruned biomass that is managed with this technique (Table 1). The main differences between conventional and organic management arise from avoided emissions from fertilizer production and increased carbon sequestration (Table 2). The absolute sequestration rate was on average very low when compared to other organic systems studied, except treenuts, due to low rates of pruning mulching and particularly of cover crop cultivation, which are the lowest of all organic groups (29\%).

The average net global warming potential of $158 \mathrm{~g} \mathrm{CO}_{2} \mathrm{e} /$ $\mathrm{kg}$ of conventional grapes is in the lower range of the published values analyzed by Rugani et al. (2013) and also lower than those calculated by Villanueva-Rey et al. (2013) for conventional grape production in NW Spain. These differences are probably caused by the low input use in the studied systems. The global warming potential was reduced to $113 \mathrm{~g} \mathrm{CO}_{2} \mathrm{e} / \mathrm{kg}$ under organic management, but this value is still higher than the ones reported for biodynamic farming by Villanueva-Rey et al. (op. cit.), mainly due to reduced machinery use under biodynamic management. In addition, Bosco et al. (2013) have shown that grape production emissions could be offset by carbon sequestration if adequate agronomic practices are applied, suggesting that the systems we studied were far from their mitigation potential.

\subsubsection{Olives}

The studied olive systems show the maximum difference in carbon footprint between conventional and organic management. The carbon footprint per kilogram of product averaged 324 and $-10 \mathrm{~g} \mathrm{CO}_{2} \mathrm{e}$, respectively (Table 2 ), and the composition of the profiles also differed greatly. Olive systems have a relatively high intensification degree, which implies high emissions associated to fertilizer production under conventional management and high sequestration rate under organic management (Fig. 2a). Nonetheless, they are rainfed systems with no emissions associated to irrigation and a low direct $\mathrm{N}_{2} \mathrm{O}$ emission factor. Therefore, although absolute sequestration rates in organic citrus and fruit orchards more than doubled those of organic olive groves, the latter showed the maximum relative sequestration rates, representing an amount in terms of $\mathrm{CO}_{2} \mathrm{e}$ similar to all the other emissions produced within the system (Fig. 2b). Remarkable soil carbon accumulation in olive groves applying recommended management practices had been previously recorded in experimental studies (e.g., Palese et al. 2013; García-Ruiz et al. 2012). LozanoGarcía and Parras-Alcántara (2013) showed that organic olive orchards can accumulate even more carbon in the soil than environmentally friendly Mediterranean dehesas. To our knowledge, however, no previous study had evaluated the net effect of carbon sequestration on the total greenhouse gas budget of organic olives.

\subsection{Sensitivity analysis}

\subsubsection{Carbon sequestration}

The sensitivity analysis of carbon sequestration in olive systems (Fig. 3a) showed a very high response of the global warming potential of organic olives to the change in temporal boundaries: when these were switched from a 100- to 20-year time frame, the average carbon footprint of organic olives dropped from -10 to $-275 \mathrm{~g} \mathrm{CO}_{2} \mathrm{e} / \mathrm{kg}$. This response was lower in the case of conventional olives, in which carbon sequestration is not an important fraction of the carbon footprint. Therefore, the average reduction in greenhouse gas emissions for organic over conventional increased from 103 to $186 \%$, showing the great mitigation potential of organic olive farming during the first decades after organic conversion. The comparison with gross IPCC (2006) methodology yields very similar results to ours on an aggregate scale, although individual disparities exist. The effect is higher than our estimate at 20 years but lower at 100 years, as a result of the assumption of carbon content stabilization in the 20-100year period in IPCC methodology. This assumption contrasts with modeling studies that predict that carbon will continue changing, even if at a lower rate, during the whole 100-year period (Hansen et al. 2006; Powlson et al. 2008; AlvaroFuentes and Paustian 2011).

\subsubsection{Coproduct consideration}

The sensitivity analysis of treenuts exposed in Fig. 3b reveals that the choice of the method of allocation between the main product and coproducts may have a drastic effect on the global warming potential of crop products. Allocating all emissions to nut main product (Product) resulted in similar emission levels as in the economic allocation between nuts and the wood coproducts (Economic), as the economic value of fuelwood is very low in comparison with nuts. In opposition to this lack of effect, allocation by dry matter production (Mass) greatly reduced the global warming potentials of both conventional and organic nut products when compared with those of main product allocation, in line with the high proportion represented by exported wood in the total biomass production of treenut systems (Table 1). System expansion yielded the greatest effect on the carbon footprint, which dropped to near 0 in both types of cropping systems as a result of the consideration of fuelwood as a substitute for natural gas fuel in domestic heaters. This change in the approach of the analysis also had the largest effect on the global warming potential of cereal grains coproducing straw for forage (Aguilera et al. Submitted).

The function of energy provision through woody biomass production had seldom been recognized in the assessment of the global warming potential of fruit tree orchards, despite that 

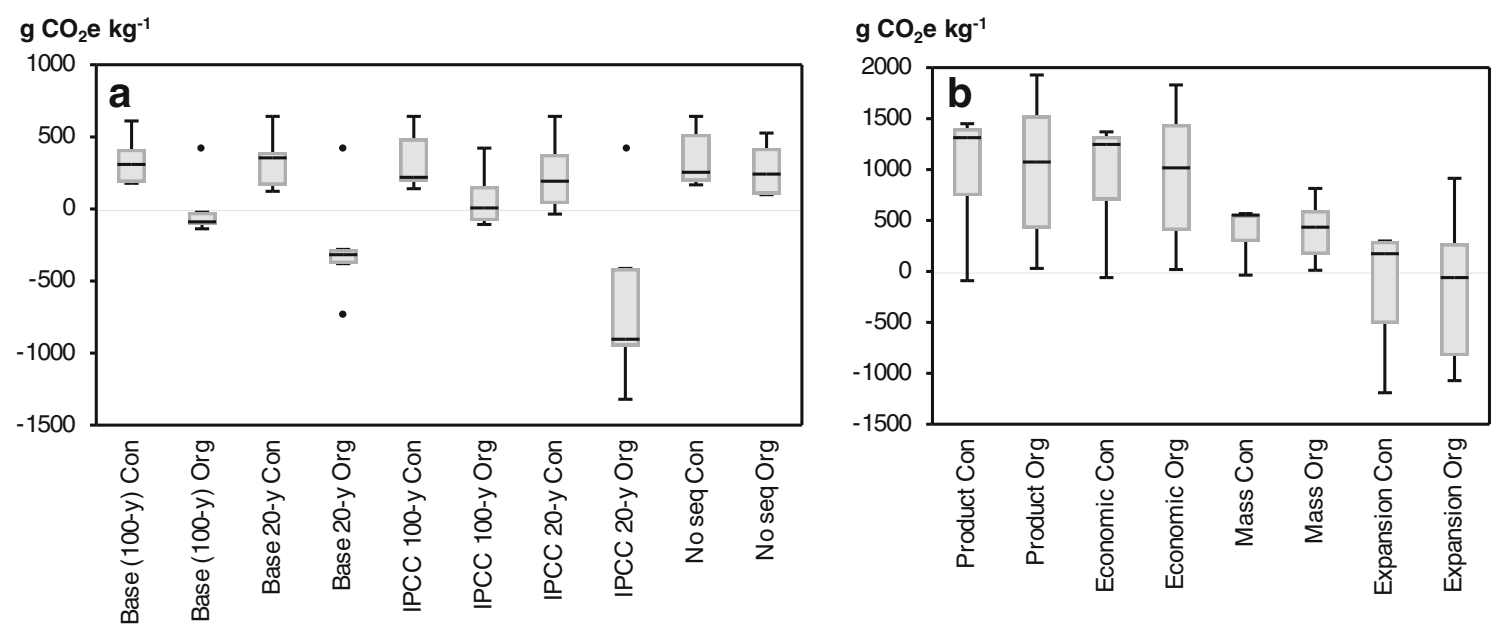

Fig. 3 Sensitivity analysis of the global warming potential $\left(\mathrm{g} \mathrm{CO}_{2}\right.$-eq $\left./ \mathrm{kg}\right)$ of conventional (Con) and organic (Org) management of a olives as affected by different estimations of carbon sequestration and $\mathbf{b}$ tree nuts as affected by changes in coproduct consideration. Olive scenarios are compared to Base (100-y), which represents base case sequestration, and include base case sequestration for the initial 20-year period (Base 20-y); IPCC sequestration estimates for 100- and 20-year time horizons (respectively, IPCC 100-y and IPCC 20-y); and no sequestration (No seq).

some studies have addressed the role of biomass accumulation in the carbon footprint (e.g., Palese et al. 2013) and other have estimated the potential for energy use of residual woody biomass (Kroodsma and Field 2006). Our results show that woody systems in Spain are already providing significant amounts of renewable energy to society, whose value in terms of saved greenhouse gas emissions may reach a similar magnitude than the emissions arising from crop cultivation.

\subsection{Identifying the potential for improving the carbon footprint}

Our results show a high response of the carbon footprint to differences in management, in line with other studies on greenhouse gas emissions from orchards (e.g., Mouron et al. 2006). Carbon sequestration was the greatest contributor to reduced global warming potential under organic farming in most of the studied systems (citrus, fruits, vineyards, olives), while energy-related emissions were smaller contributors. In addition, fruit tree orchards produce residues that can be burned in substitution of fossil fuels or temporally sequestered as wood products. The studied perennial systems show a large global warming mitigation potential, which has been only partially realized up to now.

\subsubsection{Carbon sequestration in organic and conventional farming}

The difference between organic and conventional systems in carbon sequestration rate estimated for the initial 20-year period after conversion averaged $0.29 \mathrm{Mg} \mathrm{C} / \mathrm{ha}$, which is
Treenut coproduct scenarios include product allocation (Product), in which all emissions are allocated to the main product; economic allocation (Economic); mass allocation (Mass); and system expansion (Expansion) in which wood coproducts are assumed to substitute natural gas for domestic heating purposes. Lines represent medians; boxes represent the 25th to 75th percentiles, non-outlier ranges (whiskers), outliers (dots), and extremes (asterisks)

below the world average of $0.45 \mathrm{Mg} \mathrm{C} / \mathrm{ha}$ obtained by Gattinger et al. (2012) in an extensive meta-analysis, and similar to the Mediterranean average of $0.31 \mathrm{Mg}$ for experimental studies reported by Aguilera et al. (2013a). In our greenhouse gas emission balance, however, we adopted a time frame of 100 years, which resulted in an average sequestration rate of $0.14 \mathrm{Mg} \mathrm{C} / \mathrm{ha}$. In addition, some of our assumptions were low when compared with other published data, for example, carbon sequestration associated to cover crops (González-Sánchez et al. 2012). Even with these conservative estimates, the results show how the magnitude of soil carbon sequestration in Mediterranean organic systems is often similar to that of the aggregate of all other emissions in the balance, potentially resulting in carbon neutral products. Carbon sequestration offset 9 to $102 \%$ of emissions in the studied organic categories (Fig. 2a), with an average of $38 \%$. Negative net emission values were observed in nine cases under organic management (six olives, two vineyards, and one fig tree) and in two cases under conventional management (one carob tree and one vineyard). In other climates, potential carbon sequestration in orchards could be similar or even higher than in Mediterranean systems (Leinfelder et al. 2012), but its relative role in the net carbon footprint will depend on the levels of the other components of the balance.

High $\mathrm{C}$ sequestration rates in organic woody systems were primarily explained by the use of cover crops and the application of pruning residues to the soil. In organic farms, the combined use of both techniques resulted in an average emission of $39 \mathrm{~g} \mathrm{CO}_{2} \mathrm{e} / \mathrm{kg}$ of product, compared with $129 \mathrm{~g}$ in those applying one of them and $815 \mathrm{~g}$ in those not applying any of them. The associated changes in SOC almost always 
represent genuine $\mathrm{CO}_{2}$ mitigation because the standard practices are to maintain the soil bare and burn the pruning residues. Furthermore, these practices have additional positive outcomes for erosion reduction, biodiversity enrichment, and yield increase. In our study, however, many organic farmers did not apply all possible practices $(65.1 \%$ of organic farms used cover crops and $57 \%$ incorporated pruning residues), suggesting a large potential for improvement.

\subsubsection{Cover crops}

The possibility of maintaining cover crops between trees and below tree canopies is a clear advantage for carbon sequestration in woody cropping systems. Cover cropping can increase total biomass production in the agroecosystem while reducing external resource use in mechanical or chemical weeding operations, as well as in $\mathrm{N}$ fertilizers. In the studied Mediterranean orchards, the carbon footprint of organic products benefit from a greater adoption degree of cover crops. The carbon footprint of the organic products cultivated with full cover cropping averaged $77 \mathrm{~g} \mathrm{CO}_{2} \mathrm{e} / \mathrm{kg}$ compared to $509 \mathrm{~g} \mathrm{CO}_{2} \mathrm{e} / \mathrm{kg}$ of organic products cultivated without cover crops. Our results suggest that the increase in $\mathrm{N}_{2} \mathrm{O}$ emissions resulting from the extra $\mathrm{N}$ inputs from legume cover crops is much lower than the effect on soil carbon in terms of global warming potential.

Besides the effects on mitigation, the agronomic benefits of cover cropping also extend to aspects related with adaptation and other ecological services, such as reduced soil erosion, increased water infiltration, and enhanced $\mathrm{N}$ retention. However, there is a concern among farmers about the yield effect of water competition with the main crop, particularly in rainfed systems. Yet, these possible impacts can be overcome by an adequate timing of cover crop management operations, while the farm may have an additional output in the form of forage if the cover is grazed (Ramos et al. 2011).

\subsubsection{Residual biomass}

Soil application of pruning residues leads to a significant enhancement of C stocks (Palese et al. 2013) and avoids trace gas emission from biomass combustion. Our results indicate that this practice can greatly improve the greenhouse gas emission balance of cropping systems when compared to open burning of the residues. Furthermore, additional woody residual biomass is nowadays contributing to renewable energy production in growing areas through the generalized use of thick pruning residues and of wood from plantation removals, with significant climatic benefits by preventing fossil fuel emissions (Fig. 3b). We did not specifically compare the performance of soil application with the energetic use of the residues. In any case, decision making for the destiny of the residues should differentiate their different fractions and take into account multiple factors such as the actual use, the feasibility of management operations, the nutrient content, the need to increase soil organic matter in vulnerable Mediterranean soils, and the availability of solar and wind resources as alternatives for energy production in Mediterranean areas.

On the other hand, the self-supply of nutrient and carbon inputs can be enhanced in those crops whose products are transformed by agro-industry. This is especially true for olives, as the olive oil production process generates a waste that contains virtually all nutrients of the fruit, but also applies to grapes and other fruits for the production of wine and juices, respectively. Residues can be added to the soils after adequate treatment, such as composting, resulting in a very high increase in soil carbon and soil quality (García-Ruiz et al. 2012), while helping to avoid fertilizer use and environmental problems associated to residue management.

\subsubsection{Bridging the yield gap}

Lower yields reduced the climatic performance of organic systems. The type of fertilizer does not seem to represent a driver of the yield gap between organic and conventional production that we found, as other studies under Mediterranean conditions have shown that yields are not affected by fertilizer type and could even be increased by the presence of organic inputs (Palese et al. 2013; see also Aguilera et al. 2013b). Therefore, there is a need for more research in order to close this yield gap; e.g., in irrigated organic fruits, this gap is mainly due to pest and disease problems, which are not well controlled. Making the most of the potential of woody system features to enhance and close nutrient cycles would also certainly help to improve yields. Efforts to enhance yields, however, should also account for the multifunctional character of woody cropping systems, which can provide not only the crop products quantified as yields, but also fuel, feed, materials, and important ecological services. Adequate arrangements of available techniques to optimize this multifunctionality would greatly reduce total land requirements of organic systems, as has been studied in olive orchards (Guzmán et al. 2011). These changes require participative research and extension efforts in order to fine-tune management operations to site-specific characteristics and to spread the knowledge among farmers.

\subsubsection{Reducing fossil fuel emissions in the farm and in the food chain}

Fossil energy use represented a large share of emissions in the analyzed systems, despite somewhat lower than in herbaceous crops of the same area (Aguilera et al. Submitted). Mitigation measures similar to those described in Aguilera et al. (op. cit.) 
could also be applied in woody systems to reduce this consumption and its associated emissions, including approaches related to the reduction in energy use and those focused on the substitution of fossil energy by renewable energy. This would help to achieve significant net carbon sequestration at the farm level, which is an important step since this stage usually represents a large share of emissions associated to food consumption (Rugani et al. 2013), and it is virtually the only one that can act as a carbon sink. In spite of this, further reductions in other stages of the food chain are needed in order to extend carbon neutrality to the full life cycle of food products. These actions should be taken in coherence with agricultural measures and would include cutting fossil fuel use through energy efficiency and renewable energy in agro-industry, shortening transport distances, and applying integrated waste management.

\section{Conclusions}

Our results draw a panoramic picture of the greenhouse gas balance of perennial woody cropping systems in Spain, as an illustrative example of a Mediterranean producing country. Distinctive emission profiles could be identified according to the types of crops, management (organic or conventional), and irrigation regimes. The degree of adoption of management techniques involving the increase of organic matter inputs to the soil exerted a profound influence on the total global warming potential through their effect on $\mathrm{C}$ sequestration, which can fully offset the rest of life-cycle emissions of woody crop products. The results of this work show how organic management in Spain is generally more efficient in developing the climate change mitigation potential than conventional management, due to a greater degree of adoption of techniques such as cover cropping and pruning residue recycling. Nevertheless, there is a high variability in the application of these practices and subsequently in the estimated carbon footprints of the different products. Therefore, there is still much way to further improve climatic performance through the expansion and improvement of these and other techniques. The drastic differences in $\mathrm{C}$ footprints observed between different management choices suggest that bold policy measures are justified. In this sense, the organic regulation in Mediterranean woody agriculture could make cover cropping mandatory and restrict the open burning of biomass. These measures should be accompanied by support for transitioning and might be extended to conventional agriculture if the huge potential for climate change mitigation by Mediterranean woody systems is to be boosted.

The present work reveals the importance of coproducts in the carbon footprint assessment of Mediterranean woody crop products, both from a methodological and from a practical point of view. The full exploitation of the multiple woody crop coproducts would mean a return to the logic of traditional multifunctional Mediterranean woody cropping systems. In the present ecological and economic crisis, there is an urgent need to guarantee the provision of multiple ecosystem services, including food, feed, energy, materials, carbon storage, biodiversity conservation, and soil protection against erosion. The new techniques and knowledge, such as pruning residue chipping tools, cover crop management expertise, composting methods, efficient biomass boilers, or even more sophisticated techniques such as pyrolysis, could make the most of this logic in order to upgrade the provision of services from woody systems to the new necessities of modern society. This transition is knowledge intensive because it has to integrate and optimize multiple functions in varied environments, so it would greatly benefit from policies supporting the production and diffusion of this information.

Acknowledgments This study was funded by the Canadian Social Sciences and Humanities Research Council through the project 8952011-1020 Sustainable farm systems: long-term socio-ecological metabolism in western agriculture. We would like to thank Dr. Luis Lassaletta for his helpful comments.

\section{References}

Aguilera E, Lassaletta L, Gattinger A, Gimeno BS (2013a) Managing soil carbon for climate change mitigation and adaptation in Mediterranean cropping systems. A meta-analysis. Agric Ecosyst Environ 168:25-36. doi:10.1016/j.agee.2013.02.003

Aguilera E, Lassaletta L, Sanz-Cobena A et al (2013b) The potential of organic fertilizers and water management to reduce $\mathrm{N}_{2} \mathrm{O}$ emissions in Mediterranean climate cropping systems. Agric Ecosyst Environ 164:32-52. doi:10.1016/j.agee.2012.09.006

Aguilera E, Guzmán GI, Alonso AM (2014) Greenhouse gas emissions from organic and conventional cropping systems in Spain. I. Herbaceous crops. Agron Sustain Dev. doi:10.1007/s13593-0140267-9

Alonso AM, Guzmán GI (2010) Comparison of the efficiency and use of energy in organic and conventional farming in Spanish agricultural systems. J Sustain Agric 34:312-338. doi:10.1080/ 10440041003613362

Alvaro-Fuentes J, Paustian K (2011) Potential soil carbon sequestration in a semiarid Mediterranean agroecosystem under climate change: quantifying management and climate effects. Plant Soil 338:261272. doi:10.1007/s11104-010-0304-7

Bilandzija N, Voca N, Kricka T et al (2012) Energy potential of fruit tree pruned biomass in Croatia. Span J Agric Res 10:292-298. doi:10. 5424/sjar/2012102-126-11

Bosco S, Di Bene C, Galli M et al (2013) Soil organic matter accounting in the carbon footprint analysis of the wine chain. Int J Life Cycle Assess 18:973-989. doi:10.1007/s11367-013-0567-3

CAPMA (2013) Observatorio de precios y mercados. Consejería de Agricultura, Pesca y Desarrollo Rural de la Junta de Andalucía. http://www.juntadeandalucia.es/agriculturaypesca/observatorio/ servlet/FrontController?ec $=$ default\&action $=$ Static \&url $=$ introduccion.jsp. Accessed 5 Feb 2014

ecoinvent Centre (2007) ecoinvent data v2.0. ecoinvent reports no. 1-25. Swiss Centre for Life Cycle Inventories, Dübendorf 
FAO (2014) FAOSTAT food balance sheets. Part of FAOSTATFAO database for food and agriculture. Rome: Food and agriculture Organisation of United Nations (FAO). Available: http:// faostat3.fao.org/faostat-gateway/go/to/download/FB/*/E. Accessed 15 Jan 2014

Fernández-Escobar R (1988) Planificación y diseño de plantaciones frutales. Mundi-Prensa, Madrid

García-Ruiz R, Victoria Ochoa M, Belen Hinojosa M, Gómez-Muñoz B (2012) Improved soil quality after 16 years of olive mill pomace application in olive oil groves. Agron Sustain Dev 32:803-810. doi: 10.1007/s13593-011-0080-7

Gattinger A, Muller A, Haeni M et al (2012) Enhanced top soil carbon stocks under organic farming. Proc Natl Acad Sci U S A 109: 18226-18231. doi:10.1073/pnas.1209429109

González-Sánchez EJ, Ordoñez-Fernández R, Carbonell-Bojollo R et al (2012) Meta-analysis on atmospheric carbon capture in Spain through the use of conservation agriculture. Soil Tillage Res 122: 52-60. doi:10.1016/j.still.2012.03.001

Guzmán GI, Alonso AM (2008) A comparison of energy use in conventional and organic olive oil production in Spain. Agr Syst 98:167176. doi:10.1016/j.agsy.2008.06.004

Guzmán GI, González de Molina M, Alonso AM (2011) The land cost of agrarian sustainability. An assessment. Land Use Policy 28:825835. doi:10.1016/j.landusepol.2011.01.010

Guzmán GI, Aguilera E, Soto Fernández D et al (2014) Working paper No. 2: methodology and converters to calculate the net primary productivity (NPP) of the agro-ecosystems. Sociedad Española de Historia Agraria - Documentos de trabajo, DT-SEHA, 1407

Hansen TL, Bhander GS, Christensen TH et al (2006) Life cycle modelling of environmental impacts of application of processed organic municipal solid waste on agricultural land (EASEWASTE). Waste Manag Res 24:153-166. doi:10.1177/0734242x06063053

Infante-Amate J, González de Molina M (2013) The socio-ecological transition on a crop scale: the case of olive orchards in Southern Spain (1750-2000). Hum Ecol 41:961-969. doi:10.1007/s10745013-9618-4

Infante-Amate J, Soto Fernández D, Iriarte-Goñi I et al (2014) La producción de leña en España y sus implicaciones en la transición energética. Una serie a escala provincial (1900-2000). Asociación Española de Historia Económica

IPCC (2006) Guidelines for national greenhouse gas inventories. Agriculture, forestry and other land use, vol 4. Intergovernmental Panel on Climate Change, Japan

Kroodsma DA, Field CB (2006) Carbon sequestration in California agriculture, 1980-2000. Ecol Appl 16:1975-1985. doi:10.1890/ 1051-0761(2006)016[1975:CSICA]2.0.CO;2

Leinfelder MM, Merwin IA, Brown MG (2012) Soil health indicators, apple tree growth, and carbon sequestration differ among orchard groundcover management systems. In: Welbaum GE, Nektarios PA, Monteiro JA, Fernández Escobar R (eds) XXVIII International horticultural congress on science and horticulture for people, pp 333-339

Lozano-García B, Parras-Alcántara L (2013) Land use and management effects on carbon and nitrogen in Mediterranean Cambisols. Agric Ecosyst Environ 179:208-214. doi:10.1016/j.agee.2013.07.009

MAGRAMA (2009) Observatorio de precios de los alimentos. Ministerio de Agricultura, Alimentación y Medio Ambiente, http://www. magrama.gob.es/es/estadistica/temas/estadisticas-alimentacion/ observatorio-precios/default.aspx. Accessed 5 Feb 2014

MAGRAMA (2011) Anuario de estadística agraria. Ministerio de Agricultura, Alimentación y Medio Ambiente, Madrid

MARM (2008) Inventario de emisiones de gases de efecto invernadero de España 1990-2006. Ministerio de Medio Ambiente, Medio Rural y Marino, Madrid

Mouron P, Nemecek T, Scholz RW, Weber O (2006) Management influence on environmental impacts in an apple production system on Swiss fruit farms: combining life cycle assessment with statistical risk assessment. Agric Ecosyst Environ 114:311-322. doi:10.1016/ j.agee.2005.11.020

Muñoz-Rojas M, De la Rosa D, Zavala LM et al (2011) Changes in land cover and vegetation carbon stocks in Andalusia, Southern Spain (1956-2007). Sci Total Environ 409:2796-2806. doi:10.1016/j. scitotenv.2011.04.009

Nemecek T, Weiler K, Plassmann K et al (2012) Estimation of the variability in global warming potential of worldwide crop production using a modular extrapolation approach. J Clean Prod 31:106117. doi:10.1016/j.jclepro.2012.03.005

Noponen MRA, Healey JR, Soto G, Haggar JP (2013) Sink or sourcethe potential of coffee agroforestry systems to sequester atmospheric $\mathrm{CO}_{2}$ into soil organic carbon. Agric Ecosyst Environ 175:60-68. doi:10.1016/j.agee.2013.04.012

Palese AM, Pergola M, Favia M et al (2013) A sustainable model for the management of olive orchards located in semi-arid marginal areas: some remarks and indications for policy makers. Environ Sci Pol 27: 81-90. doi:10.1016/j.envsci.2012.11.001

Pergola M, D'Amico M, Celano G et al (2013) Sustainability evaluation of Sicily's lemon and orange production: an energy, economic and environmental analysis. J Environ Manage 128:674-682. doi:10. 1016/j.jenvman.2013.06.007

Powlson DS, Riche AB, Coleman K et al (2008) Carbon sequestration in European soils through straw incorporation: limitations and alternatives. Waste Manag 28:741-746. doi:10.1111/j.1365-2389.2010. 01342.x

PRè Consultants (2010) SimaPro life cycle analysis version 7.2 (software)

Ramos ME, Altieri MA, Garcia PA, Robles AB (2011) Oat and oat-vetch as rainfed fodder-cover crops in semiarid environments: effects of fertilization and harvest time on forage yield and quality. J Sustain Agric 35:726-744. doi:10.1080/10440046.2011.606490

Roccuzzo G, Zanotelli D, Allegra M et al (2012) Assessing nutrient uptake by field-grown orange trees. Eur J Agron 41:73-80. doi:10. 1016/j.eja.2012.03.011

Rugani B, Vázquez-Rowe I, Benedetto G, Benetto E (2013) A comprehensive review of carbon footprint analysis as an extended environmental indicator in the wine sector. J Clean Prod 54:61-77. doi:10. 1016/j.jclepro.2013.04.036

Venkat K (2012) Comparison of twelve organic and conventional farming systems: a life cycle greenhouse gas emissions perspective. J Sustain Agric 36:620-649. doi:10.1080/10440046.2012.672378

Villanueva-Rey P, Vázquez-Rowe I, Moreira MT, Feijoo G (2013) Comparative life cycle assessment in the wine sector: biodynamic vs. conventional viticulture activities in NW Spain. J Clean Prod 65: 330-341. doi:10.1016/j.jclepro.2013.08.026 